\title{
QIKJS-Part.0.D
}

\section{Qualitative Inquiry of Korean Judicial System}

\author{
Kiyoung Kim \\ Professor of Law and Public Policy \\ Dept. of Law, Chosun University \\ Gawng-ju South Korea
}

\section{Articles and Annotated Bibliography}

Burt, R. (1999). The social capital of opinion leaders. Annals of AAPSS, 566, 37-54.

The article discusses the role and benefit of opinion leaders in terms of policy diffusion and social capital. It identified two very different network mechanisms in which contagion by cohesion plays to inform the group and contagion by equivalence does to generate its adoption. The role of opinion leaders, however, is superficial that is brokering the information between the groups and resembles the network entrepreneurs. The article led the followers to be productive by using its analogy and framing on the complementary content of diffusion and social capital research.

The author brought together two lines of work - research on the network structure of interpersonal contagion and research on the network structure of social capital that was intended to offer new perspective on opinion leaders (Burt, 1999). The two important concepts in the network structure of contagion include equivalence and cohesion. Cohesion refers to the strength of relationship between ego and alter. Equivalence refer to ego's and alter's having similar relationships with other people. Between these two concepts, we can draw on three significant points of comparison between cohesion and equivalence. First, there are situations in which cohesion and equivalence make identical contagion predictions. Therefore equivalence equals cohesion. Second, there are situations in which cohesion predicts contagion and equivalence does not. Therefore, equivalence corrects cohesion. Third, there are situations in which equivalence predicts contagion and cohesion does not. Therefore, equivalence extends cohesion. The author discusses the illustrative evidence from the major empirical studies, which cover the medical innovation, business and politics (1999). For example, cohesion is superfluous between strongly equivalent doctors since competition between strongly equivalent people can be expected to make them so aware of one another's behavior that socializing communication is superfluous to contagion between them. In the business, empirical findings show equivalence is a strong factor that contagion occurs than cohesion. The elite lobbyists had been studied to prove the contagion thesis, and the evidence of contagion by equivalence is the more similar evaluations by strongly equivalent lobbyists relative to nonequivalent lobbyists. The author's theme is that the results highlight the brokerage role of opinion leaders. Citing the work of King and Summers, the author brought to attention, "In most contexts, the notion of an opinion leader dominating attitudes or 
behaviors in his social network overstates the power of interpersonal communication (p. 42)." One other line of work is about the network structure of social capital, in which career and income advantages are associated with playing the role of opinion broker and as termed social capital. The structural holes from weak connections are an opportunity to broker the flow of information between people and control the form of projects that bring together people from opposite sides of holes. With the role of opinion broker, the information and control benefits occur by bridging the structural holes, and they often enjoy a competitive advantage if with stronger network connections across structural holes.

The article is helpful to investigate the role of opinion leaders in PAKJ. The author deals with the broker role of opinion leader and versatile responsibility, in which they enjoy a competitive advantage as the kind of social capital. It implies that the authentic leadership to reform the judicial system can be phased out in different dimension if beyond the information dimension. The kind of thought is relevant who must be ultimately responsible for the PAKJ, for example, among the social commentators, jurists or legal educators and so.

Walzer, M. (1990). The communitarian critique of liberalism. Political Theory, 18 (1), 6-23.

In the communitarian critique of liberalism, Walzer perceived that it is a consistently intermittent feature of liberal politics and social organizations like the pleating of trousers, transient but certain to return. Without it, the intellectual interchange would be nothing but an inconstant feature of liberalism. To him, the communitarianism is usefully contrasted with social democracy that liberals and social democrats alike share a commitment of economic growth and cope with deracinated social forms that growth produces. Walzer dealt with the problem of communitarian criticism today that it suggests two different and deeply contradictory arguments against liberalism (Walzer, 1990). The first argument holds that liberal political theory accurately represents liberal social practice. In his view, the members of liberal society share no political or religious traditions, and they can tell only one story about themselves and that is the story of ex nihilo creation, which begins in the state of nature or the original position. Although the communitarian critique is indeed powerful as the home of coherence, connection, and narrative capacity and as noted with the progenies of "neo prefixed" accounts, he continued on the suspect if, for example, between the community of strangers and justice or the inverse of argument on the artificial and ahistorical union out of multitude of isolated selves. The second critique is plain as holds that liberal theory radically misrepresents real life. It is plausible that liberal theory distorts our reality and insofar as we adopt the theory, deprives us of any ready access to our own experience of communal embeddedness. He, however, also is not discontent by asking how we are to understand this extraordinary disjunction between communal experience and liberal ideology, between personal conviction and public rhetoric, and social boundedness and political isolation (1990). Despite a shortcoming of two critiques, he defends, as a leading scholar of communitarianism, that those are partly right.

First, given that we are living in a profoundly unsettled society, the second argument is certainly true if the parent-based communitarian affinity is sole influence to define the person and community. ${ }^{1}$ Another approach to the truth of the second critical argument, such as Martin

1 For example, the best predictor of how people will vote is our knowledge of how their parents voted. The 
Luther King's speeches or language of individual rights, is not simply libertarian in essence or would be that prevents us from understanding or maintaining the ties that bind us together. In his view, liberalism is a self-subverting doctrine that, for that reason, it really does require a periodic communitarian correction. The liberal idea of voluntary association is mythical while communitarianism is the dream of a perfect free-riderness (1990). At best, the liberal society is the social union of social unions that John Rawls described; pluralism of groups bonded by shared ideas of toleration and democracy. This tarnishes the larger union and the more dissociated individuals are, the stronger the state is likely be, since it will be only or the most important social union. His discourse comes with three illustrations of state behavior, i.e., Wagner Act, use of tax exemptions, and passage of plant closing laws arguing that the state is not only social union and worse policies brought the unions, religious organizations, and neighbors to draw on feelings and beliefs that, in principle if not always in history, predate the emergence of the liberal state. He extends his critique to the political form and theory that a good liberal or social democratic state enhances the possibilities for cooperative coping. He admits that the republic terms can be suited with the accounts on the role and responsibility of non-neutral state these days (1990). However, none of the political terms is any guarantee against the erosion of the underlying communities or the death of local loyalties. In his view, it is a matter of principle that communities must always be at risk. The central issue for political theory, in sum, is not the constitution of the self but the connection of constituted selves, the pattern of social relations.

The article is relevant with my topic that the current policy environment involved in PAKJ has to be recast from the frame of thought, say, communitarianism. In the earlier years, we had been liberated and actually dominated by the liberal power of nations, and the liberal constitutionalism is some of quasi-religious belief in the public mindedness of Koreans, which is somehow natural given the communism enemy state in the north. The constitutional policy of political liberalism has been enmeshed with no contentious period of public experience, especially around 1945 through the 1960 and 1970's chilled political culture. The liberalism dictatorship, often attributed as Korean Right, had left a wake of history in the tradition of militaristic strong leadership and national development plan of economy. The times now turned on the global eighth economy and with the experimental lesson, which allows the pluralistic frame of thought to investigate the Korean essences of public policy (Kim, 2014;2015a,b). The communitarian critic could provide more perspectives or narration to discuss the Korean current.

Kymlicka, W. (1988). Liberalism and communitarianism. Canadian Journal of Philosophy, $18,181-204$.

In the liberalism and communitarianism, the author plans to examine the resources available to liberalism to meet the common objections raised by the communitarians, socialists and feminists (Kymlicka, 1988). His intellectual debts are related to the political morality of modern liberals from J.S. Mill through Rawls and Dworkin. Despite the wide variety of use of the term "liberal", he is using it in fairly restricted sense; (i) political morality (ii) modern

full liberalization of the social order, the production and reproduction of self-inventing individuals, may take a long time, much longer, indeed, than liberals themselves expected. 
liberalism, what are, in essence, new liberals or social democrats developed since 18th century other than 17 th, the period of classic liberalism. In his view, the political morality is associated with deliberation of beings. Unfortunately, however, it doesn't only take the form of asking which course of action maximizes a particular value that is held unquestioned. In other words, the concern with which we make such judgments only makes sense on the assumption that our essential interest is in living a life that is in fact good, not the life we currently believe to be good. The political morality can play with this gap, and the claim that we have an essential interest in revising those of our current beliefs about value which are mistaken is not, the author hopes, an objectionable one. ${ }^{2}$

Granted the inescapable essential interest of life "in fact good standard", we have two preconditions for its fulfillment: inside freedom and beliefs of value (ii) freedom to question those beliefs in light of information, examples and arguments our culture can provide (1988). This account of our essential interest forms the basis of liberal political theory, in which government treats people equal and the requirement of justice is primary. In this sense of frame, Unger misread by claiming "the liberals defend liberty because our choices are ultimately arbitrary, incapable of rational criticism or justification," or Jaggar's "human nature is a presocial system, which resulted eventually in the abstract individualism. ${ }^{3}$ The author argued that the purview is misconstruals of the liberal position as espoused by Mills, Rwals, Dowrkin Nozick and Raz (1988). The liberalism standing on the political morality supposes that people revise their beliefs about value and they are being made worse off by being denied the conditions necessary to freely and rationally question their commitments. Then the author claims that communitarians implausibly argue, by pointing out their five gist of criticisms, that the liberalism fails on its defense; the liberal view of the self (i) is empty (ii) violates our selfperceptions (iii) ignores our embeddedness in communal practices (iv) ignores the necessity of social confirmation of our individual judgments and (v) pretends to have an impossible universality or objectivity (1988). Against the emptiness argument, the author countered on the fallacy that being free to question all the given limits of our social institution is self-defeating. Against self-perceptions argument, the author argued it is central to the liberal view that we understand ourselves prior to our ends, in the sense that no end or goal is exempt from possible re-examination, not that we can perceive a self prior to its ends. Against the self-discovery argument, the author saw it fallible that the idea that moral reasoning is completed by this process of self-discovery seems pretty facile if nobody thinks this self-discovery replaces or forecloses judgments about how to lead one's life. Against the social confirmation argument, the author admits of difficulties on the liberalism defense, but argues that it is incompatible with the liberal vision of an undistorted transparent society since the only plausible justification for communitarian politics works behind the backs of people (1988). Against the fifth and final

\footnotetext{
${ }^{2}$ He illustrated three noted philosophers to give a ground of argument that the highest order interest of Marx and Rawls, freely creative labor and capacity to form and revise our rational plans of life is merely presumptive, and Dworkin is suspected in terms political morality since he conceived most importantly of ready-formed certain interest in individual although he surpassed those basic presumptions.

3 This point is important to divide the perspective of law and politics. Unger, Jaggar or Dworkin underscored the "certain or fixed interests of individual" while the author had a focus on the political morality embedded in the liberalism.
} 
argument accusing the liberals untenable, transcultural and ahistorical, the author raises the meaning of our moral language and questions if theory is the account of entire historical sections by contrasting between the Kantian and Hegelian notions with liberals. ${ }^{4}$ Then to the author, Roty's argument can be taken three ways - the first, about the meaning of moral language, is false; the second, about the starting point of moral conversation, is spurious; and the third, about the limits of moral conversation, is dogmatic (1988).

The article gives an insight that is crucial to review comparatively the prongs and propositions of both philosophy, i.e., liberalism and communitarianism. As seen, the latter is a powerful lens to look into the current status and challenges of PAKJ. While it is especially relevant with the maturation of Korean society on compassion and congruence, the liberalism truly is one important counter-thesis, which is indispensable to deal with the judicial system. First, the role and responsibility of jurists are generally on the right and liberty, and the constitution is still viewed as the bulwark of political liberalism. The concept of vested rights is also questioned in some distinct policy issues, such as law school reform and court fee of indigent. The new phenomenon needs to be interpreted as indebted of these perspectives that the female lawyers have a greater share in professions or two judicial supremacies. It is exciting how the communitarianism and liberalism account can view this phenomenon.

Cohen, A.J. (1999). Communitarianism, social constitution, and autonomy. Pacific Philosophical Quarterly, 80, 121-135

The author in the article discusses the ambiguity of communitarianism dealing with the thesis of social constitution thesis that participation makes us what we are. In an attempt to shed some light on it and to better understand the impact on our beliefs regarding autonomy, the author offers four possible ways and four corresponding senses of individual independence that can be compatible with the thesis of communitarianism. Hence the audience can research a moderation and compromise between marginal prongs of two theories that liberals can accept sensibly the social constitution thesis.

According to the author, the concept of autonomy is central to much contemporary political philosophy and the communitarians adhere to one central tenet that participation in society makes us what we are (Cohen, 1999). The idea common to the communitarians is the proposition that an individual being on her own cannot be a person, a human being, a self. The social constitution, in view of communitarianism, has possible meanings, if not a valid thesis, (i) it purports to explain the historic development of persons qua particulars - in other words, it is a generic claim about how an individual becomes the person she is (ii) the sustaining particular thesis is the claim that we not only become the particular persons we do in community, but that communities sustain us as the particular persons we are (1999). With possible interpretations, these two can be made into four possible meanings: genetic particular, sustaining particular, genetic general, and sustaining general. Prima facie, the social constitution theses most likely compatible with individual autonomy are the genetic particular and the genetic general these. The author then proposes three forms of independence (i)

\footnotetext{
4 He commented, "What kind of Kantian notions are involved in making such claims and why should we give them up in favor of Hegelian notions about the appeals to historical tradition?"
} 
ontological independence (ii) natural independence (iii) social independence (iv) truncated social independence (1999). From the liberalist position, it is important that for all forms of independence, the individual becomes capable of contributing to her own make-up and behavior and thus capable of being held responsible for her life and actions. While the ability of individuals to act voluntarily is important, the author viewed that individuals would fail to be able to voluntarily control their actions only under the sustaining particular thesis. Then he posited what sort of autonomy is to be encouraged by society is inexorably woven through the liberalism-communitarianism debate (1999). Since liberalism can accept either the genetic particular or the genetic general theses, it can allow for either natural or social autonomy. In view of author's perspective, the sustaining general thesis seems to be the claim communitarians most frequently or ardently articulate. They may be seen as rejecting the sustaining general thesis, as not claiming that persons are dependent upon community for their continued existence as persons, which should be unacceptable for the communitarians. We should recognize, though, that the sustaining general thesis is counterintuitive. In the end, if two theories or philosophies continue to have a distinction and merit of debate, we have to endorse awkward assumption that the communitarians could simply accept the genetic general and genetic particular theses, which is obviously unfit with their rhetoric. To the author, the liberals, such as Rawls, can also be seen odd at basic assumption that the two theories can be at best hypothetical or dogmatic (1999).

The article is relevant to my topic that gives an analogical insight in using the communitarian ideas. According to the author, the US communitarianism could be dissected into four categories, and somehow be focused on four patterns of individual contingencies and independence. Assuming that the individual can be independent in the specific community, such premise or condition is most idealistic in terms of philosophical good. Perhaps, social independence would be most ultimate status in this strife toward an idealistic community, which, however, can easily be circumvented as fragile. Although the genetic element is irrelevant since the Korean community is racially or ethically unitary as differs from the US, the sustaining element can be analogically applied to the issues of PAKJ.

Brugger, W. (2004). Communitarianism as the social and legal theory behind the German constitution. International Journal of Constitutional Law, 2, 431-460.

The author in the article explores the three basic theses of communitarianism and communitarian constitutional theory (Brugger, 2004). Given the collective changes, i.e., increasing globalization, commercialization and virtualization of all aspects life since the experience of post-World war II, the communitarianism must be subject to discussion that has stood long in the shadow of other political theories. Rather than a historical analysis, the author is concerned that attempts to offer a systemic reproduction of the current discussion of communitarianism for the purpose of illuminating the meaning of the German Constitution. In this purpose, the way of author is paved to forge an interpretation of basic law in the light of this theory and in contrast to the previously predominant viewpoints of liberalism.

First, the author dissected the communitarianism into three basic theses, say, conservative, liberal and universalistic communitarianism (2004). The first variant of communitarianism may be designated as conservative or substantive, in which it is based on the thesis that a political and legal order can only function on a long term basis when a relative degree of homogeneity exists internally, guaranteeing loyalty, mutual understanding, and care 
among citizens. The second egalitarian or universalistic variant of communitarianism emphasizes two universal postulates of equality that R. Dworkin captured with the formula "equal concern and respect" - that is to say, equal consideration of the basic needs and selfdetermination of all peoples as well as equal respect for the lifestyles of all individuals and groups (2004). This universalistic vision is not likely to occur in the foreseeable future, universalistic communitarianism accepts the current regime of nation-states. Liberal communitarianism attempts to avoid the exaggerations of the two variants by proposing on the social philosophy and legal or constitutional organization. At the level of social philosophy, the communitarians note that a human being's environment consists of several spheres of responsibility or forms of association, reaching from the single individual and its near horizon to the far horizon of human beings. Each of these communities has its own ethos and its own standards for distributing advantages and disadvantages as well as its own responsibilities (2004). According to the liberal communitarianism, the good life and an attractive social theory require a meaningful differentiation and mediation of community spheres while respecting varying moral obligations that cannot be reduced to a uniform morality of humankind.

Second, the author gave an account of the German constitution viewed in the light of liberal communitarianism (2004). The focus firstly is shed on the level of the nation state, to say, the level of organization constituted by the German Constitution. The Constitution distances itself from the concepts of closed sovereignty as promulgated by Carl Schmitt, and increasing permeability of nation states is notable for reasons currently, the internal differentiation of the individual federal states (Lander) as well as the right of self-determination at the level of the local governments (Gemeiden) though. The opening and permeation of the German Constitution by transnational obligations take place at three levels; (i) through the integration of Germany into the European Union (ii) its integration into the international community (iii) by the anchoring of human rights in the German Constitution (2004). Besides the structural issues of this kind, he also analyzed the constitutional rights among the sorts, for example, more protection of existential and loyalty-bound rights and duties as the right to vote and compulsory military service as well as the universal human rights. He argued that the conservative and liberal communitarianism actually resulted in different view about the issue of political asylum or refugees. In this way, he explores the influence of liberal and conservative communitarianism on the German Constitution (2004). The article is relevant to my topic on the similar ground with article 9 in this bibliography that engrafts the views of communitarian critique with the national basic laws. It can be more direct to inform the justices or judges at bench or bar members since the constitution as a whole was taken from the standpoint of communitarian philosophy. Nevertheless, the values or ideas can be borrowed from the German constitution and the philosophy in viewing the issues of Korean public in general, and specifically on the part of Lander in the German constitution or the process of European integration. Since the judicial system is woven with the German constitutional court or European ideas are not less over the Korean ethos and intelligence, it is useful to taste both philosophy and constitution, the kind of bible on the issues of their public lives.

Lacorix, J. (2002). For a European constitutional patriotism. Political Studies, 50, 944-958.

The author in this article identified two dominant models for understanding the source of common political identities in the European context, what are the universal paradigm of constitutional patriotism and the communitarian paradigm of civil nationalism (Lacorix, 2002). 
While the author concedes the mixed effect of these as a middle way on the European Union - gave birth to the appealing synthesis of a cosmopolitan communitarianism - the author argued that the national or communitarian challenge can better be addressed by the development of constitutional patriotism than by a loose compromise. The author thus believed that constitutional patriotism has practical significance, is historically embedded and seeks to promote a shared political culture. Over the recent years, the intellectual debate has revived spectacularly on the notion of political identity and on its articulation over cultural and national identities with the quickening pace of European integration. It brings two responses in main (2002). The first one holds the classic categories of political thought would be renewed profoundly with the opportunity, thereby allowing dissociation between the juridical order of the political community and the cultural, historical and geographical order of national identities. The second position is that of "national republicans" and "civic nationalists," who maintain that universal principles are incapable of establishing a fixed political identity.

According to the exponents of constitutional patriotism, European political identity cannot take a national shape on two accounts (2002). First, they point out that the European Union, divided in many national and subnational cultures, cannot be associated with any mythic European fatherland and even less with a European Union. Second, the champions of constitutional patriotism proposed that a political democracy does not need any identification with a peculiar historical or cultural identity -- rather needs to enhance the coexistence and the cooperation of these diverse pre-political identities. It is worth underlining that this universal paradigm of constitutional patriotism informs the current official conception of the European Union. Directly opposed to the exponents of constitutional patriotism, the national criticism from French speaking and English speaking countries presents their account toward the political identity and European integration. In the view of author, the national criticism in this heritage can be considered as an exemplar of the communitarian criticism of political liberalism. This nation-centered view is too narrow when confronted with the current mutation of democracy. In this understanding, the author pleads in favor of constitutional patriotism by challenging three of most widespread criticisms made of it. Against abstract principles criticism, the author countered that the ultimate motives are adhesion to the universal principles of human rights and democracy, neither communitarians nor nationalist motives and it never denies the importance of local, national and regional identities. Against the disencumbered idealism or ahistorical criticism, he also argues if the origin of European integration is based on history and that we need to admit the dark side of Vichy experience or British colonialism. Against the complete insulation of politics and culture and thus self-defeating criticism, the author argued that the shared political culture should emerge from an open deliberation and confrontation process among the various national cultures involved in EU far from denying the importance of national peculiarities. Then he turns to critique the propositions of two political theorists, Bellamy and Castiglione, who tried to extrapolate the conceptual dichotomy between liberals and communitarianism to EU. He argued against their view of four possible approaches to Europe and disagreed on the conclusions they made on accuse of cosmopolitan fallacy.

In his view, affiliation, membership in groups and the possibility of forming common bonds are constituent features of communitarianism regardless of what factors are accentuated in community. Between the state and community - as has important implications for jurists society and state should be constituted in such a way as to respond to human's basic need to form communities that the state is not always to be faithful as in the Hegelian fear of totalitarian 
seductions or Hitler in the world war.

The article is useful to inculcate with the depth of communitarian criticism and would be a countering view against the conceptual dichotomy between liberals and communitarian critique to EU. The article provides an insight that the philosophy, perhaps a weaker element in human or societal reality, can barely penetrate the condensed form of discussion subject or hard nature of national constitution. However, the author did not deny the persuasive power and influence of philosophy, but restrained his focus on the fallacy of dogmatic approach to the issue of EU integration from political theorists. Rather, the article vindicates the importance of culture and national history or strategies in order for the realistic understanding of political community. The EU -- now on progress for one integrated political union -- is compared in implications, with the Korean republic that can be placed, in terms of communal value sharing or common ethics, at median between the western nations and EU.

Wejnert, B. (2002). Integrating models of diffusion of innovations: A conceptual framework. Annual Review of Sociology, 28, 297-326.

The author in this article provides a conceptual framework for integrating the array of variables defined in diffusion research to explicate their influence on an actor's decision to adopt an innovation (Wejnert, 2002). Therefore, it is useful to understand the diffusion theory as applicable to the studies of PAKJ. The author proposes three components to incorporate the variables, which include characteristics of innovation itself, characteristics of innovators or actors and structural characteristics of the modern world. For example, the social entity of innovators or socioeconomic characteristic will explain for the second component as variables, and geographical stetting or political conditions came to fall within the third component. The author highlight the need in diffusion research to incorporate a fuller dealing with the focus, such as the variables' interactive character or gating function.

According to the definition of author, the diffusion of innovation refers to the spread of abstract ideas and concepts, technical information, and actual practices within a social system, where the spread denotes flow or movement from a source to an adopter, typically via communication and influence (2002). The study of diffusion had not been integral or isolated, which needs to be corrected. In the author's view, the diffusion of innovation is diverse in concepts, variables, and processes. The conceptual framework is derived by grouping diffusion variables into three major components.

Table

The Conceptual Framework of Diffusion Theory

\begin{tabular}{lll}
\hline Components & Variables & Trait of Variables \\
\hline $\begin{array}{l}\text { Characteristics } \\
\text { innovations }\end{array}$ & of public versus private consequences & $\begin{array}{l}\text { Private vs. public consequences refer } \\
\text { to the impact of an innovation's } \\
\text { adoption on entities other than the } \\
\text { actor (public consequence) versus on } \\
\text { the actor itself (private consequence) }\end{array}$ \\
\hline
\end{tabular}




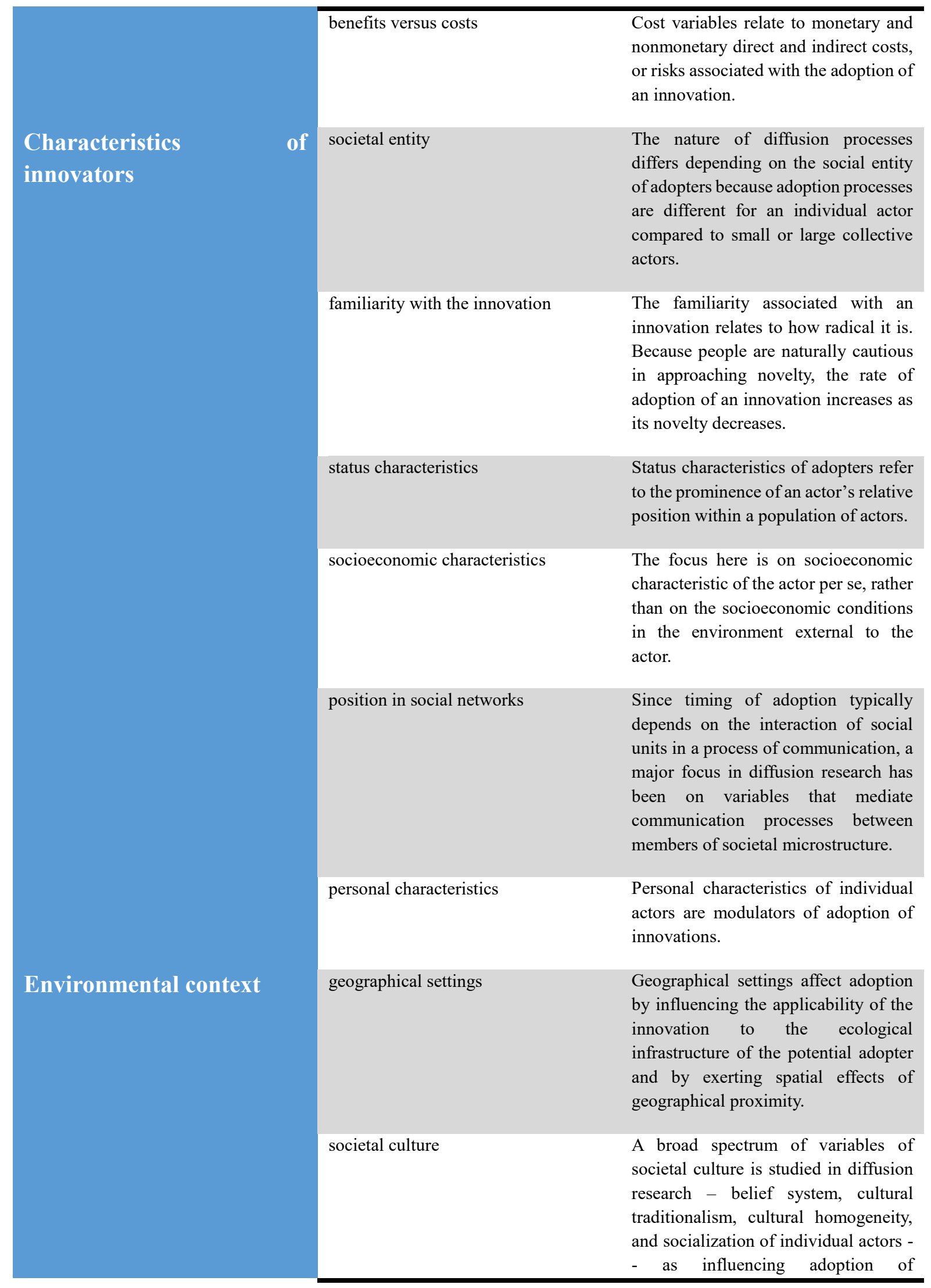




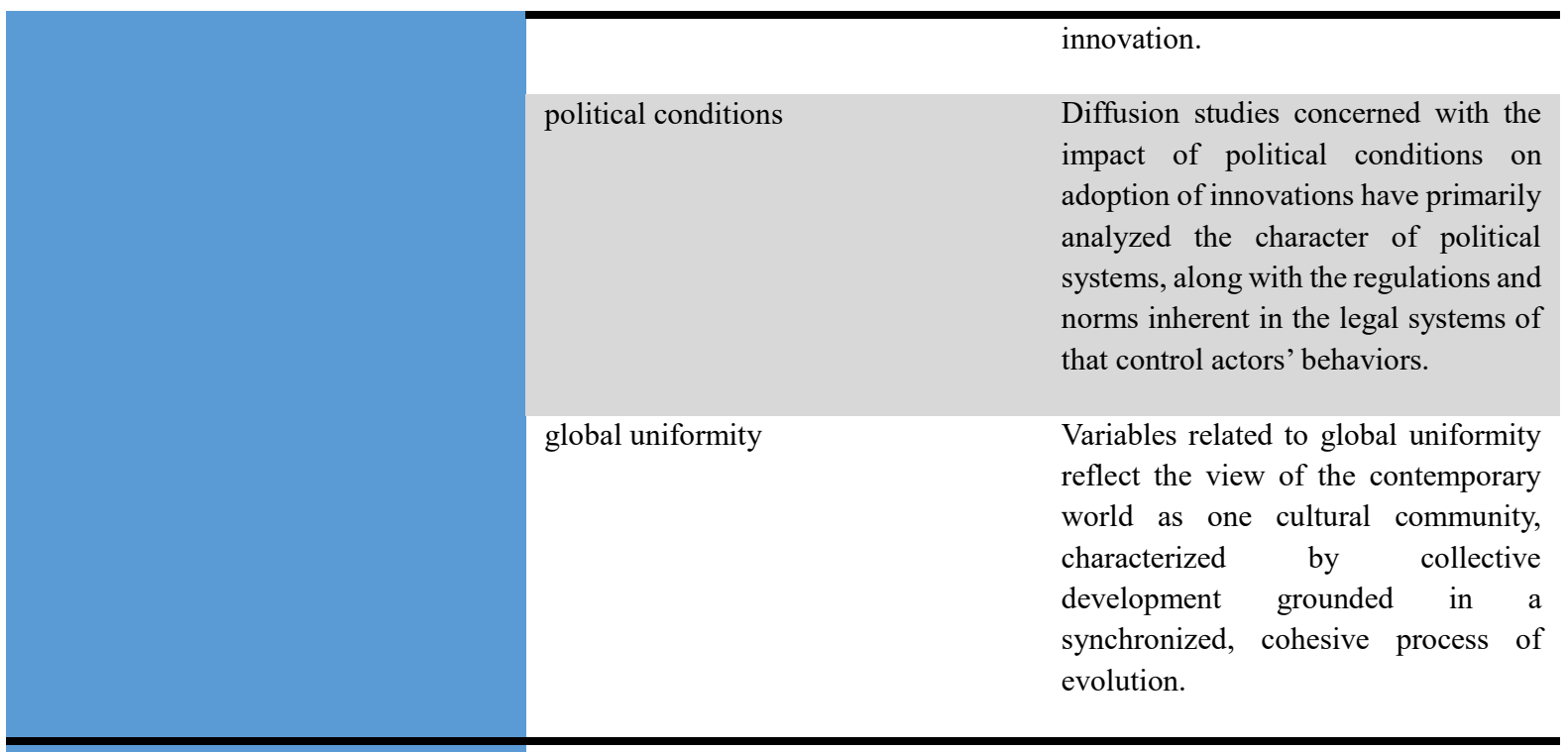

The article is useful to investigate the PAKJ in view of policy diffusion of modern judicial system. From the adoption of 1945 constitution through 1987 reform, the concepts employed by the theory of policy diffusion can bring a framed understanding of judicial system on a scientific ground. By employing those in characterizing the KJ would allow a uniform and scientific version and more persuasive account for the phenomena or system change. For example, the variables, such as political conditions or socioeconomic characteristics would be a good agent to analyze the early issues of PAKJ around 1940's. The societal culture or global uniformity can be a key concept in exploring the issue of legal globalization in recent years.

Valente, T. \& Davis, R. (1999). Accelerating the diffusion of innovations using opinion leaders. Annals of AAPSS, 566, 55-67.

The authors in this article attempt to provide the method to accelerate the diffusion of innovations using opinion leaders (Valente \& Davis, 1999). They present the optimal matching procedure and report on computer simulations that use of opinion leaders can bring a faster diffusion. As acceded, there can we be known of limitations and extensions of the model. This approach can address an inherent problem in the studies of policy diffusion that most studies have been retrospective and neglected to collect information on interpersonal communication networks.

According to the authors, many programs, interventions, and communication campaign are designed to change an organization or community by directing messages at mass or local audiences, and they have been evaluated that use mass media and/or interpersonal communication for behavior change (1999). The basic diffusion network model identify who talks to whom within the community and locate individuals who are more central to a community and thus perhaps more influential. It uses these individuals or opinion leaders to initiate the diffusion of a new idea or practice, who champions the new practice and accelerate the diffusion practice. When considering implementation of opinion leaders model, at least three factors should be considered (i) opinion leader recruitment (ii) location of training, and (iii) timing of training (1999). For example, the users of model need to consider how and where 
the learning process should take place, and whether the learning process should be static or dynamic. Getting buy-in from the opinion leaders is very important in terms of opinion leader recruitment. Despite the limitations, the model provides a means to create and chart the optimal path of diffusion within a community. For example, if diffusion cascades from the most central to the more peripheral members of the network, it can do so optimally by moving from the persons with the most nominations to those with the fewest (1999). A second advantage of this model is that in most organizations and communities, different individuals will be seen as opinion leaders in different domains. With this theory, the opportunity or burden of opinion leadership can be shared by a diverse set of individuals within the community.

The article is helpful to my topic that can provide a lens of analysis and is pertinent to suggestions or solution for the current stalemate of reform agendas. The opinion leaders could bring an impact on the agenda setting, for example, but can be merely a source to fuel in the initial stage, which must be responded by feedback and reinforcement. The checkmate or diffusion of leadership can be an alternative and one way to remedy such resilience or even intermittent abandonment. The training of leadership to cover sectors, such as college of law nationwide or professional association, as well as the governmental organs, can be networked to create a strong consensus and eventual implementation of prior vision.

Powell, K.J. (1996). The other double standard: communitarianism, federalism and American constitutional law. Seton Hall Constitutional Law, 69, 70-101.

The author in this article attempts to triangulate the communitarianism with the normative concept of federalism and American constitutional law (Powell, 1996). Provided that the theme of author deals with the federalism within the administrative and changing reality or notion, the article seems useful to understand the interplay between the judiciary and political theory as well as to explore the framework of communitarian idea and liberalism that is applicable to the studies of PAKJ.

The communitarianism was first conceived in the 1980's in reaction to the revival of normative political theory that had occurred in the previous decade and which had been dominated by proponents of liberalism (1996). On the other, the importance of federalism as a legal doctrine has steadily diminished throughout the course of American history. In this backdrop, the author aims to show how communitarianism and federalism can atone for each other's sin. The author canvasses the debate between liberals and communitarians in political theory and shows how the concept of federalism can help communitarianism answer some of major objections advanced by its opponents (1996). Both theories have a root difference in having an awareness of the nature of the self. Communitarians contend that the idea of an unencumbered self is unrealistic while contemporary liberal theorists have typically responded to these communitarian criticisms by conceding that concepts, such as the pre-social self, is mere rhetoric devices developed to demonstrate the injustice of certain political arrangements. In defining the relevant community, they have a disagreement that communitarians charge that liberalism advocates unsound principles of public policy while defenders of liberalism argue that it is impossible to identify the common good and because it is difficult to define the relevant community that shares this elusive good (1996). They also added that enforcing the public policy would constrain individual freedom to an unacceptable extent. Underlying in this disagreement is the difficult question, "whose common good?" Against the communitarian critiques, it is true that the processes of political decision-making, are thus particularly ill-suited 
to establishing consensus regarding the common good. However, so long as the political process is functioning fairly, democratic expression is an eminently reasonable and legitimate method of identifying the common good. Therefore, the notion of political communitarianism is particularly appropriate for a federal political system such as that of the United States. The author then argues that the federalism is most useful to balance the individualism and communitarianism (1996). In his view, a conception of communitarian politics founded on the jurisdictional variation allowed by a federal system of government can thus meet the most salient objections to communitarianism advanced by the doctrine's liberal critics. The author also asserted that the demise of federalism as a legal doctrine is a result of the failure of both academic and judicial commentators to appreciate a number of insights contained in a political account of communitarian theory. In the course of adapting with the purpose of article, the author dealt with the original purposes of federalism, and elucidated (i) a great portion of the substantive authority granted by the Constitution to the national government is directed to the purpose of fostering commercial development (ii) provisions granting such powers as the regulation of commerce or the coining of money represent decisions against diversity of policy in specific areas and in favor of national uniformity (iii) the bill of rights provisions as applied to the national government embody precisely the opposite preference (1996). The author also tailored his argument of the constraints on sub-national levels of government, in which he perceived the process of adopting the constitutional amendments, most stark with the fourteenth amendment, corresponds perfectly with the theory of political communitarianism. His argument on the value of communitarianism in refurbishing the federalism and national uniform public policy has been explored in the present context of two doctrines today (1996). First, given America's ideological diversity, a more principled approach to questions of national power must be adopted and that approach is found in communitarian federalism. Second, an added virtue of a communitarian account of legal federalism in contemporary constitutional law is that it prevents the notion of federalism from being employed in an instrumental or opportunistic manner. While viewing that modern constitutional law has been widely viewed as operating under a "double standard," affording great deference to governmental economic regulation, but imposing much more stringent constraints on policies that restrict civil rights and liberties, the author pointed out the judicial neglect of federalism. According to the author, however, the federalism has to be restored on the modern jurisprudence of the double standard and communitarian consensus (1996). The double standard fosters the unitary conception of political power because it embraces a topical rather than jurisdictional characterization of governmental activity. In this purview, the national government possesses only those powers specifically granted to it, while the states enjoy plenary legislative power, subject only to specifically enumerated constraints. Therefore, the acknowledgement and application of the principles of communitarian federalism in contemporary judicial review offers a mechanism to significantly alleviate the detrimental effects from the neglect of federalism.

The article is relevant with my topic that provides a lynchpin to make the philosophy be interwoven with the normative dimension, particularly the US federalism. The point of stress can share with the German constitutionalism, in which both authors have sifted two levels of constitutional structure, i.e., the bill of rights and structure of nation or constitution, as a distinct thread to be intertwined with the thought of communitarianism. For example, the federalism requires a strict scrutiny of governmental power within two sovereignties that the communitarian idea can less play out while the American community can now have a 
significant commonality on the communitarian concept of individual rights despite its cultural pluralism on race and ethnicity. In this light, the failure of uniform federal response, for example, to eliminate a gun shooting is now pushed to the corner. This idea can be applied to the poor result over a scope of reform package challenged with the judiciary, prosecution offices and bar association. The law school system may be contested in view of national communitarianism that can be variable with "sustaining general" or "sustaining particular frame"

Han, S.H. (2014). Judicial reform, wake in history and bitterness in reflection. Democracy, 5, 41-59.

The author in this article provides key events and stories of judicial reform in Korea, and highlights its continued relevance from the incomplete projects and programs to improve the judicial system standing on democracy (Han, 2014). His theme is between the juristocracy and democracy that the judicial reform should not be a familial ritual of judicial people, but be inclusive of the key requirements of democratic rule. In this standpoint of view, the author argues, for example, that the establishment of special judicial committee in 2003 is recast of its meaning since such progress created the opportunity to transfer the responsibility to the legislature from judicial bureaucrats. That fostered the political assessment and deals to redefine the details of judicial reform in Korea.

The author, in structuring his presentation, begins to overview the historical achievements and significance that has influenced the Korean judicial system through the contemporary debate (2014). From the judicial system of independence years, his view began to canvass the historical trajectory, i.e., 1987 constitutional revision and systemization on the rule of law ideals, the globalization committee in 1995 and judicial reform as a civil initiative, Judicial Reform Committee in 1999 and resilience from the judicial bureaucrats, the second Judicial Reform Committee in 2003 and unsuccessful implementation, and Special Judicial Committee of National Assembly in 2010 (2014). Along the historical meaning from the author's viewpoint, he also provides a brief of key programs and projects that bear on the continued relevance to improve the judicial system. For example, he illustrates the 53 globalization programs, in which the judicial reform to suit with the national globalization has a place (2014). It includes reform policies that will bring an increase of attorneys, new law school system to breed young lawyers, as well as a chronic bum rap embedded in the judicial practice, such as high contingency fees or nepotism on the attorney's former office. In his view, all these prospective alternatives could only be partially completed and actually remains as an encumbrance against the prototype of civil democracy. He pointed out a critical misdirection in the judicial reform that the initiative has only been held in view of political liberalism, often conceived as judicial independence and SPP in modern constitutionalism while the activism and participation of civil society largely are unsounded (2014).

The article is relevant with my topic that is projected over the historical evolution of $\mathrm{KJ}$ and key points of contention on the public policy of judicial system. The article provides a basic way of approach in consideration of PAKJ, what are a narrative and political morality of civil democracy. The author challenged the idea and practice of juristocracy in which the resilience and bureaucratic pathology can be a node of influence leading to incongruence and disagreement and disparaging the vision of Korean democrats. The article particularly would be helpful to provide not only the overview and structural consideration of my theme, in 
which we also can identify a critical point of policy dissention and key programs or agendas of Korean government on judicial reform. It could help as a prelude enabling a pilot thought on the dissertation topic. 


\section{References}

Han, S.H. (2014). Judicial reform, wake in history and bitterness in reflection. Democracy, 5, 41-59.

Powell, K.J. (1996). The other double standard: communitarianism, federalism and American constitutional law. Seton Hall Constitutional Law Journal, 7, 70-101.

Brugger, W. (2004). Communitarianism as the social and legal theory behind the German constitution. International Journal of Constitutional Law, 2, 431-460.

Kim, Kiyoung, Ethics, Law and Social Justice (April 10, 2015a). Available at SSRN: https://ssrn.com/abstract=2592876 or http://dx.doi.org/10.2139/ssrn.2592876

Kim, Kiyoung, Public Policy and Governance: Some Thoughts on Its Elements (April 3, 2015b). Available at

SSRN: https://ssrn.com/abstract=2589526 or http://dx.doi.org/10.2139/ssrn.2589526

Kim, Kiyoung, The Relationship between the Law and Public Policy: Is it a Chi-Square or Normative Shape for the Policy Makers? (September 10, 2014). Social Sciences. Vol. 3, No. 4, 2014, pp. 137-143. doi: 10.11648/j.ss.20140304.15. . Available at SSRN: $\underline{\text { https://ssrn.com/abstract }=2577832}$

Lacorix, J. (2002). For a European constitutional patriotism. Political Studies, 50, 944-958.

Walzer, M. (1990). The communitarian critique of liberalism. Political Theory, 18(1), 6-23.

Cohen, A.J. (1999). Communitarianism, social constitution, and autonomy. Pacific Philosophical Quarterly, 80, 121-135.

Kymlicka, W. (1988). Liberalism and communitarianism. Canadian Journal of Philosophy, $18,181-204$.

Valente, T. \& Davis, R. (1999). Accelerating the diffusion of innovations using opinion leaders, Annals of AAPSS, 566, 55-67.

Burt, R. (1999). The social capital of opinion leaders. Annals of AAPSS, 566, 37-54.

Wejnert, B. (2002). Integrating models of diffusion of innovations: A conceptual framework. Annual Review of Sociology, 28, 297-326. 